\title{
Index autorum
}

$(\mathrm{L})=$ Libri, $(\mathrm{R})=$ Recensores

Barry, W. J. 155 Benguerel, A.-P. 80 Biesalski, P. 129(L) Brauer, T. 129(L) Cooper, A. M. 197 Cudahy, E. 132(L) Cunningham-Andersson, U. 138 Dommelen, W. A. van 217 Engstrand, O. 138 Fischer-Jorgensen, E. 1 Fowler, C. A. 197 Fox, R. A. 97 Franke, U. 231(L) Grassegger, H. 129(R), 231(R)

Helfrich, H. 128(L) Jassem, W. 128(R) Kohler, K. J. 137 Künzel, H.J. 117 McFadden, T. U. 80

Pierrehumbert, J. B. 181 Rietveld, A. C. M. 204 Schmidt, A. M. 169 Slootweg, A. M. 204 Steele, S. A. 181 Stevens, K. 126 Svantesson, J.-O. 60 Whalen, D. H. 197 